\section{Messgerät für galvanische Abscheideprozesse}

Ein in neuartiges Prozessmessgerät stellt Somonic Solutions Evor. Die Messtechnik ermöglicht erstmals, die Geschwindigkeit von Metallabscheidungen unter Industriebedingungen zu überwachen. Zur Messung wird ein Stabsensor in den Abscheideprozess eingebracht, an dessen Spitze parallel zur Ware Metall abgeschieden wird. Durch eine fortlaufende Messung der abgeschiedenen Masse ist eine Inline-Messung der Abscheidegeschwindigkeit beziehungsweise der Stromausbeute möglich. Durch Einsatz des Messgeräts wird die Prozesssicherheit erhöht und die Beschichtungsqualität besser gesichert. Außerdem lässt sich der Anlagendurchsatz steigern und die Überbeschichtung mit teuren Metallen wird vermieden.

Tel. 035146335070

Halle 3, D 54(17)

\section{Energiesparende Kälte für die Oberflächentechnik}

\&R Kältetechnik stellt auf der Hannover Messe ein Maßnah_menpaket vor, das den Energiebedarf der Anlagen drastisch senken kann. Dazu gehören unter anderem der Einsatz von elektronisch drehzahlgeregelten Pumpen und Lüftern, die bedarfsgerechte Auswahl des Kältemittels sowie eine gleitende Kondensationsdruckregelung (Vari-Kon), die die Kondensationstemperatur an die Außentemperatur anpasst. Investitionen in derartige Energiesparmaßnahmen amortisieren sich nach Angaben des Unternehmens häufig innerhalb weniger Monate. Auch die Wärmerückgewinnung kann den Energieverbrauch eines Galvanobetriebs nachhaltig senken. Dasselbe gilt für die Winterentlastung. Sinkt die Außentemperatur auf circa $5 \mathrm{~K}$ unterhalb der Wasservorlauftemperatur, kann man in dieser Zeit komplett auf die Kältemaschine verzichten und die Kühlung erfolgt über den Freikühler. Somit lassen sich durch die Winterentlastung im Durchschnitt etwa $35 \%$ Energiekosten einsparen. Ein weiterer ist die Auswahl und Dimensionierung der Wärmetauscher an beziehungsweise in den Kühlbädern.

Tel. 02935 96614-0, www.Ir-kaelte.de

Halle 3, Stand D 54(14)

\section{Hochleistungsfähige und kompakte VE-Wasser-Aufbereitungsanlage}

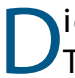
e Reinheitsanforderungen in der industriellen Teile- und Oberflächenreinigung erfordern immer mehr den Einsatz von vollentsalztem Wasser. Der Wasseraufbereitungsspezialist Orben kombiniert bei größerem VE-Wasserbedarf die Ionenaustauscher- mit der Umkehrosmose-Technologie, um VE-Wasser in einem optimalen Preis-Leistungsverhältnis zu erzeugen. Auf der Hannover Messe stellt das Unternehmen erstmals eine hochleistungsfähige Kompaktanlage (TWB-130) vor, die

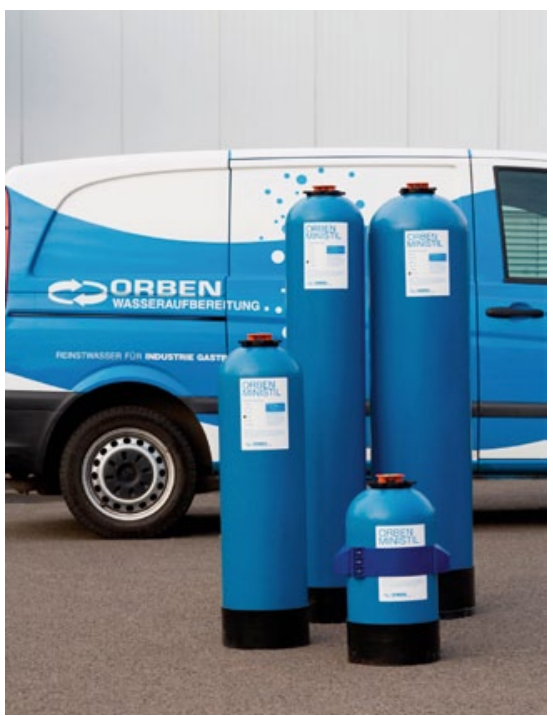

die Vorzüge beider Technologien in einer Anlage vereint. Bei einem Platzbedarf unter einem Quadratmeter erzeugt die anschlussfertige Kompaktanlage kontinuierlich bis 150 Liter pro Stunde mit einem Leitwert unter $0,2 \mu \mathrm{S} / \mathrm{cm}$. Tel. 0611 9625722, www.orben.de Halle 3, Stand D 68(1)

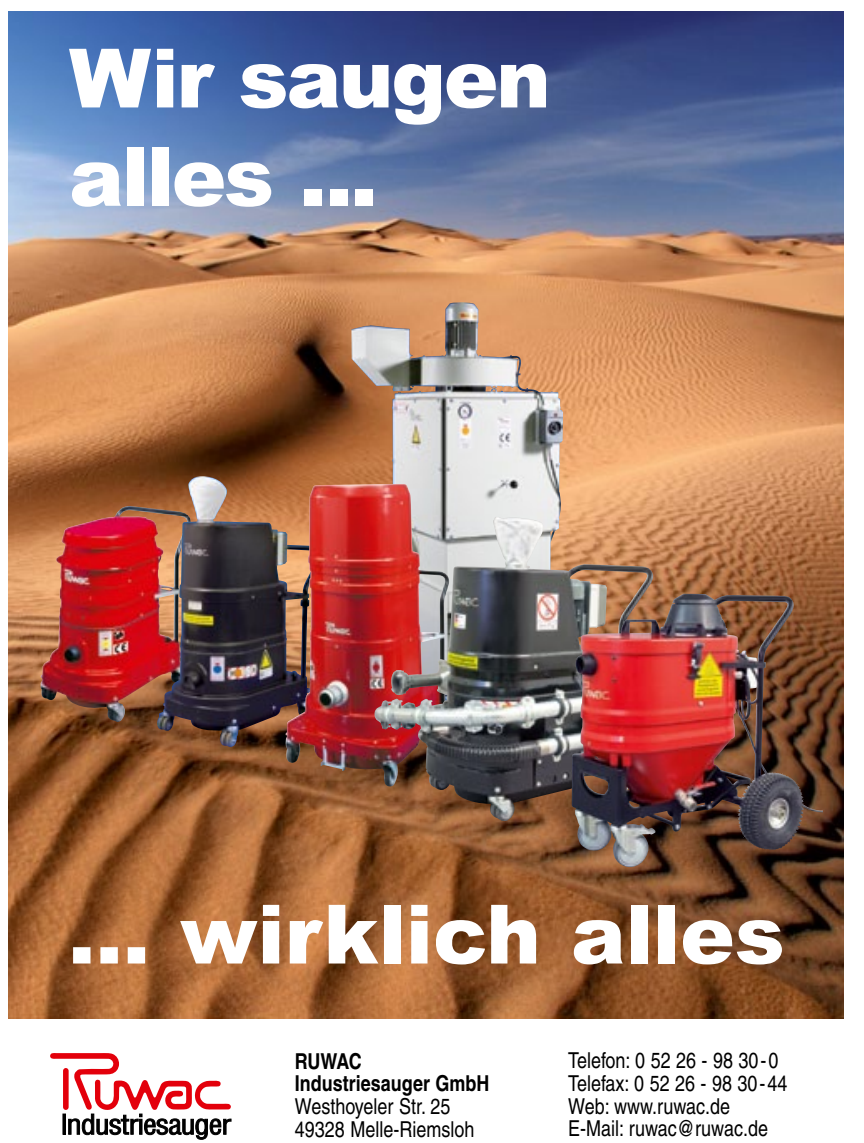

